\title{
12. Care Aesthetics in Time of COVID-19
}

\author{
James Thompson ${ }^{59}$ \\ doi.org/10.3280/oa-637-12
}

When I first started writing on the theme of care aesthetics, my purpose was to question the boundaries in social theatre between, on the one hand, the artists who had the capacity for operating in an aesthetic register and, on the other, the social, education and health workers who operated in the register of care (Thompson, 2015; Stuart Fisher and Thompson, 2020). I became interested in how artists demonstrated care in their work - whether through attention to actors, focus on objects, involvement of communities, or design of spaces. This was, of course, also an exploration of when they did not demonstrate care in their work. It valued the care taken in arts practices, but it was also a critique of when artists, who might claim they were pursuing projects of social change, showed a lack of care in their dealings with participants or the communities in which they worked. Similarly, I was interested in when social, health or care workers demonstrated an artistry or craft in their work - when they practiced with a certain attention to aesthetics and what it might mean to critique care practices for their lack of attention to a sensory experience or when they were executed without an aesthetic sensibility.

In seeking to dissolve this boundary care aesthetics was trying to imagine practices which were both caring and aesthetic without an assumption about who was automatically entitled to the designation "carer" or "artist". So, the physiotherapist could demonstrate care aesthetics in her work with a patient, as her touch and hold exhibited a certain craft. Similarly, a neighbour may cook a meal for an isolated friend which communicated her love and affection for them. A social movement might be structured with a certain care aesthetics in the beautiful way it maintains bonds and support between its activists. A community association might shape its day centre for its elderly members with attention to the look and feel of an environment in a way that

59 This essay replaces the one Thompson presented at the International Conference Performing the Social. Education, Care and Social Inclusion through Theatre held in Milan in September 2019, which will be published in extended form in TDR - The Drama Review during 2021 (Thompson, 2021). 
respected their sense of worth and sense of place. Care aesthetics was trying to get away from the idea that social theatre, applied theatre or community arts was about places empty of aesthetics inviting the artists into their midst to invigorate them with joy, play and craft - with a model that suggested there is care aesthetics in many different parts of life. The argument was that we needed to sustain our ability to care for each other, for our communities and for the worlds in which we live with great craft and skill without thinking that only those with the formal title "artist" could provide this. Of course, artists can and do provide rich care aesthetic experiences - but we need to democratise who is valued for their aesthetic work and recognise the artistry of multiple practitioners and professionals.

Of course, care aesthetics is making another claim. One that suggests that increasing the artistry that takes place between people in their communities makes healthier, potentially more equitable and joyful lives. Similarly deepening our capacities to care for each other - not as an idea but as an actual practice - can provide more sustainable, healthy neighbourhoods and more mutually enriching lives. Care aesthetics is descriptive in analysing and documenting the aesthetic experience of care in community, health and arts projects. But it is also normative - it is a proposal for change. It is suggesting that improving the aesthetic quality of care practices (whether a theatre project or a health practice) will enhance the likelihood of them offering life enhancing and transformative experiences. When the times we live in value the technical and managerial over the embodied and affective, it is a demand for a slower, more human-centred relational focus for acts of care. Similarly, it is making a demand that in a world of extremes of lack of care, and the ugliness of poverty, exclusion and discrimination, we need to improve the way we live together to ensure the damaging and unequal relations that dominate our worlds have a chance to be transformed. Care aesthetics is about the shape and feel of how we look after each other and how we look out for each other - it is about the art and craft of solidarity.

And that was before COVID-19 - before we entered what has been the biggest international crisis in care in any of our lives. It is a global event that has brought the practice, quality and fragility of the care services we all need into sharp relief. It has shown how care cannot be abstracted from the policies of our governments, our communities strengths and weaknesses and the multiple inequalities that cut through our different contexts. In March 2020, people in the UK watched the situation as it unfolded in Italy. In a classically British condescending way, our press and TV reports hinted that something particular had happened that was catastrophic because of some inherent 
problems in Italian society and its health sector and of course nothing of that scale could possibly happen in our "superior" system. Little did these commentators know then that the spectacular incompetence and arrogance of our leaders would lead to the UK becoming the worse affected country in Europe with the second highest death per capita rate (after Belgium) and the highest numbers of deaths which stands at over 45,000 at the time of writing.

In those early reports, one of the more light-hearted accounts was the images and video clips of Italian people singing and playing instruments from their balconies. While again in our reports these were tinged with both romantic and patronising notions of Italy being the home of Opera and particularly demonstrative people, I remember thinking how joyful and resistant these videos seemed. They had that wonderful "in spite of" quality familiar in arts projects that I have previously documented in war zones, where communities in spite of their terrible situation want to sing, dance and act as a way of maintaining both their sense of humanity and also their connections with others. These acts could easily be categorised as an art of resistance, or possibly an art of relief. But to me they were an example of care aesthetics in action. In a context of forced isolation, the event of coming out onto the balcony and singing can only be an attempt both to find some sense of space for yourself, but also reach out to others. At a time when touch - that basic craft of human relations - was not possible beyond one's own immediate family, singing became a way of touching others through the voice. If care is how we look out for, ensure the welfare of and maintain our social connection to others - singing became both a symbol of the demand for community connections, but also an act of making and sustaining them. The images of balconies of musicians seemed to me to be micro acts of an affective, artistic solidarity.

These micro acts also started to appear in the UK as we entered our period of intense lockdown - again often in spite of the government whose incompetence did much to undermine the communal solidarity that is required to keep a strict lock down in place. In the UK we had a weekly clap for the carers as people came to their front doors, driveways, and streets to applaud those people who were risking their lives in confronting the pandemic. While I don't want to overlook the irony of many individuals clapping the very people who through voting for the conservative government they had condemned to years of non-existent wage increases, there was still an element of positive solidarity in these and many similar events. These creative care acts might have started with clapping, but soon there were multiple examples of people playing live and recorded music, 
dancing in their streets and sharing a weekly moment of collective, if socially distanced, partying. These moments of solidarity with carers, and acts of caring solidarity with immediate neighbours, were joined with different accounts of local acts of kindness. These included baking, cooking, shopping and delivering for isolated or shielding neighbours, making signs for windows for creative walks for children, and making home-sewed protective equipment for health professionals. Why these enter the register of care aesthetics for me is that rather than a perfunctory effort of providing basic provisions, there were multiple accounts of the special effort people put into the craft of these acts. Cakes and meals were made with an attention to their quality and presentation - the aesthetics of the acts of kindness seemed to reach beyond the demand to meet material needs. Care needed a sense of focus and attention - a crafted concern - for both the carer and cared-for to realise a more poignant and powerful sense of connection.

In my local community a bike courier service was started delivering provisions from local traders to people in need, sometimes free meals from local restaurants or groceries for people too unwell to venture out. The volunteers behind this new venture, including my partner who was part of the organising team, knew that it was not just a matter of getting care packages to their recipients, but also the quality of the engagements they had with both traders and people in their houses. In a world when standard means of community relations and interhuman contact were radically altered, they provided an interaction between people - a quality caring relation that prioritised moments of human contact where time was not a constraining factor. These were small but vital networks of solidarity in difficult times. In another example, a friend set up a network of sewers to create scrubs for health care workers. They were largely machinists from an area in North Manchester where they had traditionally worked in the different clothes factories, and now their skills were gaining recognition and being valued for the contribution to the safety of other carers. Again, it was not merely the sewing up of the protective gear and getting it to the staff, but also the attention and care with which these garments were made. Their craft of care became a means to reach out and connect to people who, of course, should have had adequate Personal Protective Equipment as part of their employment - but who had often been left to fend for themselves by poorly coordinated services. Stepping into a gap with these beautifully and carefully made scrubs was also an act of resistance to the incompetence of our government. 
All these examples illustrate different elements of care aesthetics. The value of craft skills, the way that their execution is often more than the basic required as people make an extra effort both for their personal sense of worth, but also for how that effort communicates your affection for and solidarity with the person to whom you are sending the materials. And then they are about an aesthetics of relations. The objects created certainly had an aesthetic quality - the scrubs, the meals, the cakes, the masks, the care packages, and the shopping bags - were all prepared with an attention to their quality, shape and look. However, more than in the quality of these objects, care aesthetics is also located in the relation that is created between the person, the object and their recipient. The interaction that is made possible by these multiple acts becomes the source of the embodied care that is experienced between different people meeting the challenges of the situation. A person to person conversation on a door step - perhaps an act of kindness while providing a parcel of goods - is an aesthetic engagement because it is attuned to the sensory needs of both parties, and it has a style, approach, a narrative and regard for the emotional and affective shape of the encounter.

Some might argue that in locating aesthetic experiences in these everyday acts during COVID-19 I am ignoring the work of artists - and that artists too have been involved in responding to the pandemic. There is no doubt they have - they have created amazing online and physical responses, and of course their livelihoods have been appallingly affected by the lockdowns and the ongoing demands of social distancing. The point to emphasise is that care aesthetics is not just about the arts, it is about the artistry of carers and the care of artists - and the craft of the care that many others exhibit in the community-based solidarities in which they are involved. Also, what is important to reemphasise here is that care aesthetics is both a descriptive and normative, that is evaluative, account. So, the examples I gave above were largely where the aesthetics of the care was notable for the positive connections and affective resonances it made. We could describe an encounter between two people as perfunctory and absent of any care craft. Care can be done poorly, and of course at worse it can be a location of abuse or cruelty. In discussing care aesthetics, it is important to criticise the inequalities in caring relations (both poorly paid carer to wealthy cared-for, and powerful carer to vulnerable cared-for) and note the embodied, sensory nature of the practices that are part of neglectful care. Linking this back to artists, they can create artistic projects that demonstrate an astounding positive care aesthetics, that create experiences for groups, communities and our wider society that enable and champion beautiful caring relations between people. My point is that they cannot be assumed to be doing this - 
they might act selfishly, created hierarchical relations between themselves and others, or create work that exhibits neglect and poor treatment of others. Care aesthetics seeks to challenge artists, carers and citizens more broadly to attend to the relations we create with others, our mutual interdependence, and consider how its shape, craft, sensory and embodied elements, enhance our abilities to live mutually enriching, safe, just and more fulfilled lives. COVID-19 has provided this challenge - and in many ways, in diverse places, people have shown that human relations can be about creative, artistic and imaginative forging of caring bonds between people.

We are going to need the strength of these acts of affective solidarity in the difficult months, and certainly years, ahead. 